\title{
Effect of time, amount and frequency of feeding on total egg production, fertility and hatchability in broiler breeders
}

\author{
Majid Gholami Soltanmoradi ${ }^{1}$, Alireza Seidavi', Mohammad Dadashbeiki², Fernando \\ Delgado $^{3,4}$ and Sandra Gamboa ${ }^{3,4}$
}

'Department of Animal Science, Islamic Azad University, Rasht Branch, Rasht, Iran, ${ }^{2}$ Department of Veterinary Science, Islamic Azad University, Rasht Branch, Rasht, Iran, ${ }^{3}$ Animal Reproduction Laboratory, Department of Zootechnic Sciences, Agricultural School, Polytechnic Institute of Coimbra, Coimbra, Portugal, ${ }^{4}$ CERNAS - Center Studies of Natural Resources, Environment and Society, Polytechnic Institute, Coimbra, Portugal

\begin{abstract}
The effects of timing, the amount and the frequencies of feeding on the performance of broiler breeders (Ross 308) at the age of 31-38 weeks were studied. The broiler breeders were randomly assigned to each of 15 treatments $(\mathrm{T})$. These included day feedings, in which birds were fed once at $4.00(\mathrm{~T} 1=$ control), twice ( $\mathrm{T} 2 \mathrm{to} \mathrm{T} 7)$, thrice a day (T8 to $\mathrm{T} 13)$ and four ( $\mathrm{T} 14$ and T15) times per day. The daily feed allotment was divided into different ratios with different time schedules. The nutritional composition of all experimental groups was similar. Eggs were collected at $8.00,10.00,14.00$ and 16.00 . The results obtained showed that feeding schedule resulted in significant differences $(P<0.05)$ in egg production (\% hen), as well as in fertility and hatchability. Results obtained in our study suggest that allocation of restricted feed two times a day, in a 75:25 ratio (4.00 and 12.00$)$ improved egg production, fertility and hatchability.
\end{abstract}

Keywords: broiler breeder, feeding schedules, egg production, fertility, hatchability

Abbreviation: T: treatment

Archiv Tierzucht 56 (2013) 102, 1014-1022

doi: $10.7482 / 0003-9438-56-102$

Corresponding author:

Sandra Gamboa; scgamboa@esac.pt

Animal Reproduction Laboratory, Department of Zootechnic Sciences, Agricultural School, Polytechnic Institute of Coimbra, Bencanta, 3040-316 Coimbra, Portugal
Received: 15 September 2013

Accepted: 18 November 2013

Online: 20 November 2013

○) 2013 by the authors; licensee Leibniz Institute for Farm Animal Biology (FBN), Dummerstorf, Germany. This is an Open Access article distributed under the terms and conditions of the Creative Commons Attribution 3.0 License (http://creativecommons.org/licenses/by/3.0/). 


\section{Introduction}

In broiler breeders, violating the principles of feeding can result in some unfavourable characteristics such as multiple ovulation and reduced fertility. Broiler breeders are capable of releasing two or three to four follicles per day instead of releasing only one follicle per day. This characteristic occurs when the feeding is over the required amount of energy consumption and it is often accompanied by obesity. In practice, the negative consequences of multiple ovulations are as follows: the production of double yolk eggs which have no application of hatchability and an erratic pattern of egg lying since many of the follicles are lost. Overfeeding can result in the formation of bigger follicles and in some cases, it can result in the formation of two or three replicate hierarchies present in birds fed close to ad-libitum. This issue is so important that overfeeding as little as $10 \%$ can cause an increase in multiple ovulations which is the reason for the decrease in the amount of eggs with good hatchability and also for the irregularity of the laying. Besides those effects it also increases body weight and the egg laying between 15.00 to 6.00 , as well as it reduces both sperm reserves in the sperm storage glands and mating activities and consequently fertility (Leeson \& Summers 2009).

The feed-restriction practices in poultry industry can lead to a decrease in the total egg production, even though the daily feeding is a restriction method with strong interest for broiler breeder hens. Some authors say that even short-term fasting is responsible for the loss of egg production in fasted birds, since the reproductive capability of chickens may be compromised (Tanabe et al. 1981).

In an everyday feeding program the feed is rapidly consumed and the hens will fast for an extended period of time before their next meal. Moreover, females might not be fed to the proper amount due to competition among them. Splitting the daily feed allotment can ensure that a sufficient volume of feed is provided at each feeding time to minimize competition among the hens. However, the effect of feeding more than once a day is still controversy. Cave (1981) and De Avila et al. (2003) did not found any significant difference in total egg production between broiler breeder hens fed either once or twice a day. Nevertheless, Spradley et al. (2008) found that birds fed twice a day laid more eggs through 42 weeks of age than those fed once a day at the same age $(P<0.05)$. Moradi et al. (2013) also observed that total day egg production in hens fed twice and thrice a day was greater than in those in a once a day feeding program (67.1 and 67.2 vs. 62.2 eggs/hen, $P<0.01)$. Similarly, egg weight was higher $(P<0.01)$ in birds fed more than once a day. However, no differences in fertility and in hatchability were found for the time of oviposition (Zakaria et al. 2005).

Feeding time seems to have the potential to influence the performance of adult broiler breeder flocks and it is thus of great importance (Backhouse \& Gous 2006). Formerly, feeding breeders in the late afternoon was a standard procedure, but latter studies show that choice of feeding time for adult breeders can influence the production of settable eggs, egg shell quality, fertility and hatchability (Leeson \& Summers 2009). Moreover, later feeding times may delay the time of oviposition. The more important concern raised by the feeding in the late afternoon is the probable reduction of mating activities and the increase of the amount of the broken eggs. Generally, mating activity is greatest in late afternoon. If hens are more interested in feeding at this time, then there can be a reduced mating activity and also more 
aggression between males (Leeson \& Summers 2009). Additionally, the later the hens are fed the higher are the chances for the production of eggs with abnormal shells resulting in a reduction in hatchability (Clunies et al. 1993).

To our knowledge, no experiment has been conducted about the effects of timing, the amount and frequency of feeding of broiler breeder flocks on their reproductive performance. Accordingly, the aim of this experiment was to study the effects of timing, the amount and frequency of feeding on the fertility and the time of laying eggs of the broiler breeders.

\section{Material and methods}

\section{Bird husbandry}

The experiment was conducted on Ross 308 broiler breeder flocks ( 420 hens and 60 roosters) during 31th to 38th week of age. The females and males had average weights of 3,300 grams and 4,200 grams, respectively. These birds were randomly assigned to 15 treatment groups, with four replicates per treatment and seven hens and a rooster per replicate. The birds were housed in a fenced hall, $2.8 \times 45 \times 12 \mathrm{~m}$ in dimension, with cages measuring $200 \times 150 \mathrm{~cm}$ and placed in a row at 1.1 meter above the ground level, equipped with nipple drinker systems (for water ad libitum consumption), elevated perches and 16 nests. Fresh air was provided by fan-powered ventilation and room temperature was maintained with a Priva heater unit. Room's cleaning and disinfection programs were carried out in accordance with current standards. The daily photoperiod consisted of $13 \mathrm{~h}$ of light and $11 \mathrm{~h}$ of darkness till 22nd weeks of age and continued with $15 \mathrm{~h}$ of light and $9 \mathrm{~h}$ of darkness from $23 \mathrm{rd}$ week till the end of the experiment.

\section{Feeding schedules}

Fifteen feeding schedules were applied as it is shown in Table 1. Briefly, the first treatment ( $\mathrm{T} 1=$ control) consists of one feeding per day ( 4.00 with $100 \%$ of the diet in the unique meal), the 2 nd treatment includes two feedings per day (two equal meals at 4.00 and 16), and so on such as for the 15th treatment which includes four feedings per day $(4.00,8.00,12.00$, and 16.00 as much as $50 \%, 17 \%, 17 \%$ and $17 \%$ of the total diet respectively).The composition of the diet used throughout the experiment (for males and females) is shown in Table 2.

\section{Studied traits}

The traits measured were: the percentage of fertility, the percentage of hatchability and egg laying. They were recorded in five different fixed times: 8.00, 10.00, 12.00, 14.00 and 16.00.

For determining the percentage of fertility, 30 eggs of each experimental treatment were selected and put into the incubator. The eggs were individually candled at day 12 and the empty eggs were removed. The percentage of fertility was obtained from the relationship between the number of fertile eggs and the total number of eggs placed in an incubator.

The percentage of hatchability was calculated based on the percentage of eggs which actually hatched out as live young: number of eggs hatched/number of fertile eggs. 
Table 1

Timetable and amount of feed in each treatment

\begin{tabular}{lcccccccc}
\hline & \multicolumn{9}{c}{ Feeding periods and partial amount fed } & \multicolumn{2}{c}{} \\
Treatments & $\begin{array}{c}\text { First meal } \\
\text { \% of total } \\
\text { feed }\end{array}$ & $\begin{array}{c}\text { Feeding } \\
\text { time }\end{array}$ & $\begin{array}{c}\text { Second meal } \\
\text { \% of total } \\
\text { feed }\end{array}$ & $\begin{array}{c}\text { Feeding } \\
\text { time }\end{array}$ & $\begin{array}{c}\text { Third meal } \\
\text { of total } \\
\text { feed }\end{array}$ & $\begin{array}{c}\text { Feeding } \\
\text { time }\end{array}$ & $\begin{array}{c}\text { Fourth meal } \\
\text { of total } \\
\text { feed }\end{array}$ & $\begin{array}{c}\text { Feeding } \\
\text { time }\end{array}$ \\
\hline 1 (Control) & 100 & 4.00 & - & - & - & - & - & - \\
2 & 50 & 4.00 & 50 & 16.00 & - & - & - & - \\
3 & 75 & 4.00 & 25 & 16.00 & - & - & - & - \\
4 & 50 & 4.00 & 50 & 12.00 & - & - & - & - \\
5 & 75 & 4.00 & 25 & 12.00 & - & - & - & - \\
6 & 75 & 6.00 & 25 & 16.00 & - & - & - & - \\
7 & 50 & 6.00 & 50 & 16.00 & - & - & - & - \\
8 & 50 & 4.00 & 25 & 12.00 & 25 & 16.00 & - & - \\
9 & 33 & 4.00 & 33 & 12.00 & 33 & 16.00 & - & - \\
10 & 25 & 4.00 & 50 & 12.00 & 25 & 16.00 & - & - \\
11 & 25 & 4.00 & 25 & 12.00 & 50 & 16.00 & - & - \\
12 & 50 & 6.00 & 25 & 12.00 & 25 & 16.00 & - & - \\
13 & 33 & 6.00 & 33 & 12.00 & 33 & 16.00 & - & - \\
14 & 33 & 4.00 & 22 & 8.00 & 22 & 12.00 & 22 & 16.00 \\
15 & 50 & 4.00 & 17 & 8.00 & 17 & 12.00 & 17 & 16.00 \\
\hline
\end{tabular}

Table 2

Composition of the diet used in all treatments

\begin{tabular}{lclr}
\hline Ingredient, $\%$ & Amount & Nutrients & Amount \\
\hline Corn & 65.67 & Energy, kcal/kg & 2800.00 \\
Soybean meal & 19.00 & Protein, \% & 14.00 \\
Wheat & 2.00 & Calcium, \% & 3.00 \\
Wheat bran & 2.85 & Available phosphorus, \% & 0.35 \\
Supplement (mineral + vitamin) & 0.50 & Sodium, \% & 0.16 \\
Calcium carbonate & 4.11 & Chlorine, \% & 0.21 \\
Oyster & 3.00 & Potassium, \% & 0.69 \\
DCP & 1.32 & Arginine, \% & 0.94 \\
Methionine (NIK) & 0.07 & Lysine, \% & 0.73 \\
Salt & 0.25 & Methionine, \% & 0.31 \\
Baking soda & 0.12 & Methionine+cysteine, \% & 0.58 \\
Antioxidants & 0.02 & Threonine, \% & 0.55 \\
Toxin binder & 0.10 & Tryptophan, \% & 0.16 \\
& & Isoleucine, \% & 0.62 \\
& & Coline, \% & $500+975$ \\
& & Fat, \% & 2.51 \\
& & Fiber, \% & 3.35 \\
& & Linoleic acid, \% & 1.40 \\
\hline
\end{tabular}




\section{Statistical analysis}

Evaluation index and sub-ordinate functions were used for comparison of the traits, quantitatively and qualitatively (Excel software). Index values (EI) for assessing the performance of broiler breeders was calculated as follows:

$$
E l=(A-B) / C \times 10+50
$$

where $A$ is the average of specific traits, $B$ is the average of total specific traits, $C$ is the standard deviation and 50 is the fixed number (Mano et al. 1993).

Sub-ordinate function was calculated as follows (Gower 1971):

$$
X u=(X i-X \min ) /(X \max -X \min )
$$

where $X u$ is the amount of the sub-ordinate function, $X i$ is the amount of the tested traits of the treatments, and $X$ min and Xmax are the minimum and maximum amount of the traits among all the tested treatments.

The evaluation index and sub-ordinate function values for fertility and hatchability were calculated separately and an average index value was obtained. Based on the values obtained, ranks were given for each treatment.

Data related to the measured traits were analysed by SAS statistical software (SAS Institute Inc., Cary, NC, USA) and mean values were compared by Tukey test. The statistical design used was a completely randomized design and the statistical model was as follows:

$$
X_{i j}=\mu+\delta_{j}+e_{i j}
$$

where $\mu$ is the average of the total population, $\delta_{\mathrm{j}}$ is the effect of the experimental treatment and $e_{i j}$ is the effect of experimental error.

\section{Results}

The effect of frequencies of feeding on the time of laying eggs

The application of restricted nutrition in form of more than one feeding per day resulted in changes in the daily times of laying eggs at $8.00,10.00,12.00,14.00$ and 16.00 . The frequency of feeding affected the time of oviposition in broiler breeders $(P<0.05)$ except at 12.00 (Table 3). Comparison of experimental treatments in terms of the number (data not shown) and the percentage of produced eggs during the total period of rearing (31-38 weeks) resulted in highest values at 8.00 ( 22.53 eggs for each female and $47.61 \%$ of laying) and lowest values at 16.00 ( 2.46 eggs for each female and $5.24 \%$ of laying). Statistical analysis showed that $85.85 \%$ of the eggs were laid till 12.00. However, feeding more than twice a day (treatments T8 to T15) resulted in a better performance at 16.00 in terms of the number and the percentage of laying eggs (Table 3 ).

\section{The effect of frequencies of feeding on the fertility and hatchability}

Data obtained from the analysis of fertility and hatchability are presented in Figure 1. The results obtained for fertility and hatchability of broiler breeders at the age of 38 weeks showed that more than one feeding per day had a significant effect in fertility and hatchability 
Table 3

Effect of feeding time and frequency on the mean ( \pm SE) of egg production (\%) in broiler breeder from 8.00 to 16.00

\begin{tabular}{|c|c|c|c|c|c|}
\hline Treatment & 8.00 & 10.00 & 12.00 & 14.00 & 16.00 \\
\hline 1 (Control) & $45.39^{\text {defg }} \pm 0.63$ & $21.95^{\text {abcde }} \pm 0.13$ & $16.88^{\mathrm{a}} \pm 0.49$ & $10.15^{\mathrm{abcd}} \pm 0.35$ & $5.62^{\mathrm{abc}} \pm 0.45$ \\
\hline 2 & $48.03^{b c d} \pm 0.7$ & $22.10^{\mathrm{abcde}} \pm 0.36$ & $16.99^{\mathrm{a}} \pm 0.56$ & $9.08^{\mathrm{abcd}} \pm 0.37$ & $3.81^{\text {cde }} \pm 0.46$ \\
\hline 3 & $50.08^{a b c} \pm 0.45$ & $23.16^{\mathrm{abc}} \pm 0.92$ & $15.66^{\mathrm{a}} \pm 0.90$ & $7.03^{\text {cde }} \pm 1.12$ & $4.08^{\mathrm{cd}} \pm 0.62$ \\
\hline 4 & $50.87^{\mathrm{ab}} \pm 0.57$ & $24.43^{\mathrm{a}} \pm 0.50$ & $15.28^{\mathrm{a}} \pm 1.32$ & $7.11^{\text {cde }} \pm 0.82$ & $2.32 d^{e} \pm 0.48$ \\
\hline 5 & $52.70^{\mathrm{a}} \pm 0.92$ & $22.40^{\mathrm{abcd}} \pm 0.43$ & $16.67^{a} \pm 0.68$ & $6.47^{e} \pm 0.60$ & $1.76^{\mathrm{e}} \pm 0.65$ \\
\hline 6 & $50.15^{\mathrm{abc}} \pm 0.35$ & $23.36^{\mathrm{ab}} \pm 0.49$ & $16.15^{\mathrm{a}} \pm 0.54$ & $6.30^{\mathrm{e}} \pm 0.76$ & $4.05^{\mathrm{cd}} \pm 0.26$ \\
\hline 7 & $51.02^{\mathrm{ab}} \pm 0.69$ & $22.91^{\mathrm{abc}} \pm 0.68$ & $15.23^{\mathrm{a}} \pm 0.36$ & $6.63^{\mathrm{ed}} \pm 0.82$ & $4.22^{\mathrm{cd}} \pm 0.71$ \\
\hline 8 & $48.57^{\mathrm{bcd}} \pm 0.42$ & $22.11^{\text {abcde }} \pm 0.71$ & $16.82^{\mathrm{a}} \pm 0.67$ & $7.92^{\text {bcde }} \pm 0.56$ & $4.60^{b c d} \pm 0.41$ \\
\hline 9 & $48.53^{\mathrm{bcd}} \pm 1.04$ & $20.34^{\text {bcde }} \pm 0.90$ & $16.56^{\mathrm{a}} \pm 0.32$ & $8.13^{\text {bcde }} \pm 0.52$ & $6.45^{\mathrm{abc} \pm 0.88}$ \\
\hline 10 & $45.11^{\text {defg }} \pm 0.87$ & $21.68^{\mathrm{abcde}} \pm 0.49$ & $18.05^{\mathrm{a}} \pm 0.52$ & $10.53^{\mathrm{abc}} \pm 0.82$ & $6.63^{b c d} \pm 0.67$ \\
\hline 11 & $44.50^{\mathrm{efg}} \pm 0.38$ & $20.09^{\text {cde }} \pm 0.16$ & $17.21^{\mathrm{a}} \pm 0.17$ & $12.21^{\mathrm{a}} \pm 0.52$ & $5.99^{a b c} \pm 0.49$ \\
\hline 12 & $47.76^{\text {bcde }} \pm 1.01$ & $22.05^{\text {abcde }} \pm 0.77$ & $16.17^{\mathrm{a}} \pm 1.30$ & $8.69^{\text {abcde }} \pm 0.76$ & $5.34^{b c} \pm 0.96$ \\
\hline 13 & $46.83^{\text {cdef }} \pm 0.58$ & $20.45^{\text {bcde }} \pm 0.76$ & $15.16^{\mathrm{a}} \pm 0.62$ & $9.38^{\mathrm{a}} \pm 1.26$ & $8.18^{\mathrm{ab}} \pm 0.29$ \\
\hline 14 & $43.52^{\mathrm{fg}} \pm 0.87$ & $19.23^{e} \pm 0.61$ & $17.68^{\mathrm{a}} \pm 0.19$ & $11.49^{\mathrm{ab}} \pm 0.48$ & $8.08^{\mathrm{ab}} \pm 0.69$ \\
\hline 15 & $43.35^{9} \pm 0.32$ & $19.49^{\mathrm{ed}} \pm 0.16$ & $15.07^{a} \pm 0.56$ & $12.61^{\mathrm{a}} \pm 0.30$ & $9.48^{\mathrm{a}} \pm 0.31$ \\
\hline SEM $^{\mathrm{a}}$ & 47.76 & 21.72 & 16.37 & 8.91 & 5.58 \\
\hline$C V^{b}, \%$ & 0.40 & 0.23 & 0.20 & 5.88 & 5.61 \\
\hline
\end{tabular}

In each column, the averages with different letters indicate significant differences $(P<0.05)$ between treatments. astandard error of the mean, ${ }^{b}$ coefficient of variation

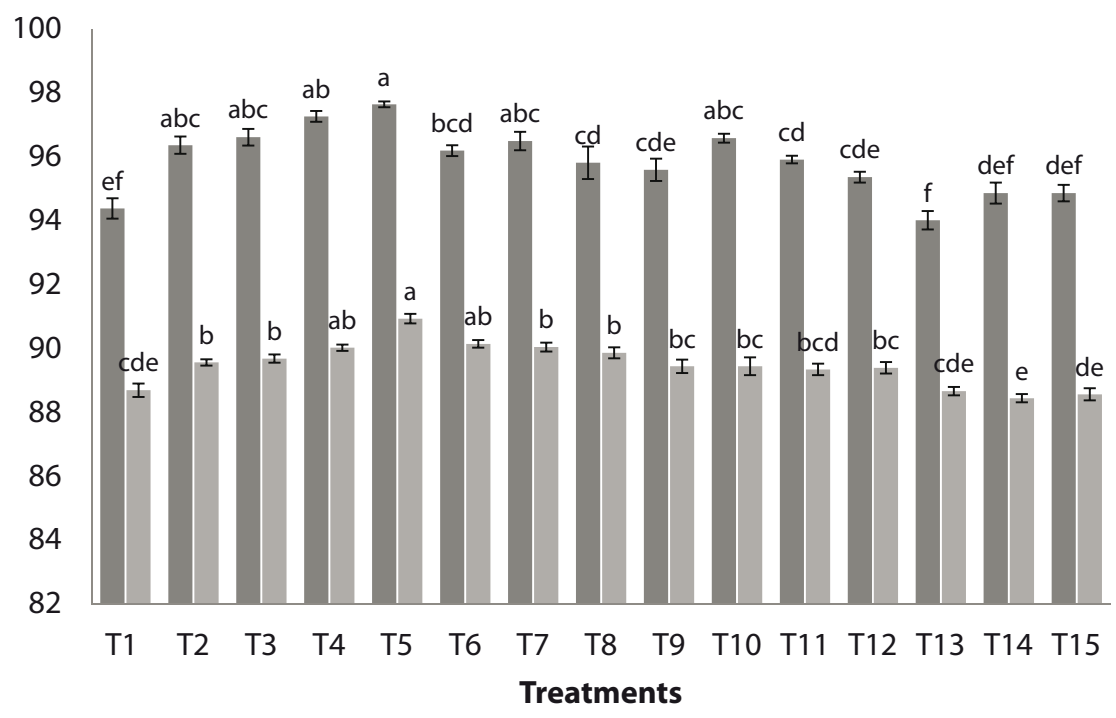

Fertility Hatchability

For both fertility and hatchability, different letters indicate significant differences $(P<0.05)$ between treatments.

Figure 1

Effect of feeding time and frequency on the mean $( \pm \mathrm{SE})$ of the reproductive performance 
$(P<0.05)$ (Figure 1). Twice feedings per day (treatment T5) had a higher percentage of fertility and hatchability in comparison with both the control (T1) and T6 treatment, and with thrice (T8, T9, T11 to T13) and four times feedings per day (T14 and T15) $(P<0.05$; Figure 1). Percentage of fertility and hatchability in treatments T14 and T15 (four times feedings per day) did not differ significantly from the control treatment, $\mathrm{T1}(P>0.05)$. Feedings of broiler breeders hens thrice a day with equal amounts of feed (at 6.00, 12.00 and 16.00, treatment T13) resulted in the lowest fertility (despite no significant differences from the control treatment and T14 and T15) while the lowest value for hatchability was observed in treatment T14 (despite no significant differences from the control treatment and T13 and T15). When feeding allowance is twice per day and the interval between the two feeding times is higher than $8 \mathrm{~h}(\mathrm{~T} 2, \mathrm{~T} 3, \mathrm{~T} 6$ and T7), fertility and hatchability decreased, but not significantly (Figure 1).

In this experiment, ranks of feeding treatments for both fertility and hatchability were based on the evaluation index and sub-ordinate function methods. Evaluation index values ranged from 174.43 (T5) to 79.42 (T13) for fertility and ranged from 205.16 (T5) to 56.95 (T14) for hatchability. Treatment T5 has shown higher index values for fertility (1.00) and hatchability (1.00) whereas T13 (0.00) and T14 (0.00) showed lower index values for fertility and hatchability, respectively. Treatment $\mathrm{T} 5$ had the highest scores for the evaluation index and the sub-ordinate methods ( 379.58 and 2.00 , respectively). Thus, this treatment is the best treatment for fertility and hatchability.

\section{Discussion}

Broiler breeder genetic strains have specific management methods associated with them. Since ad libitum feeding of broiler breeders can cause distress, they are fed restrictively early in life to limit the incidence of reproductive disorders and excessive body weight gain and to optimize reproductive performance. However, egg production can be affected by many other external factors such as specific feed ingredients, bird age and flock management decisions. Small degrees of over or under feeding have been shown to negatively impact egg production (Renema et al. 2008). Modern broiler breeder hens are typically provided a restricted amount of feed once a day. Cave (1981) demonstrated that feeding broiler breeder hens three times a day increased egg production during the first 10 weeks compared with hens fed once or twice a day. Spradley et al. (2008) reported that broiler breeders fed twice a day laid more and heavier eggs during 42 weeks of age than those fed once a day. They believed that increased egg weight was related to providing feed later in the day (15.00). Time of feeding is another important factor in broiler breeder hens, considering that shell formation normally commences in the afternoon or evening (Bootwalla et al. 1983). As a result, broiler breeders hens seem to present a feed intake pattern influenced by oviposition: feed intake is decreased $2 \mathrm{~h}$ prior to and increased for 4 $\mathrm{h}$ after oviposition (Savory 1977). Brake (1985) found a significant interaction between time of oviposition and feeding time (8.00 versus 13.00$)$ and stated that oviposition time was modified somewhat by feeding time. However, delaying feeding may delay oviposition; moreover, if the laying eggs occur after the final egg collection of the day, these eggs remain on the floor or in the cages until the first collection of next day with negative implications for fertility and hatchability. 
In our study, the application of restricted nutrition in form of more than one feeding per day resulted in changes in the daily times of laying eggs at 8.00,10.00, 14.00 and 16.00. Overall, our results shown that $85.85 \%$ of the laid eggs were obtained until 12.00 which is consistent with the time required for the process of shell formation.

Differences in total egg production were observed in our study. Hens fed two times a day (earlier in the morning and at 12.00) had better egg production compared with those fed once, thrice and four times a day. Our results are consistent with previous reports related to feeding regimens on reproductive performance. Those studies suggest that allocation of restricted feed two times a day improve reproductive performance in broiler breeder hens (de Avila et al. 2003, Spradley et al. 2008, Taherkhani et al. 2010, Moradi et al. 2013). In our study the best performance was achieved with $75 \%$ of feed allowance at 16.00 and $25 \%$ at 12.00 .

Fertility and hatchability are interrelated heritable traits that vary among breed, variety and individuals (King'ori 2011). Hatchability can be influenced by many factors including the fertility of the breeders and the shell quality. In order to omit the effect of the fertility of the roosters, they were periodically changed between pens.

Results suggest that feeding hens thrice and four times a day has no advantages compared with a twice a day feeding program. Moreover, broiler breeder hens feed twice a day showed a higher percentage of fertility and hatchability in comparison with the control group. Treatments with feed allowance until 12.00, inclusive (T4 and T5) had a higher rate of fertility and hatchability in comparison with the other treatments that included afternoon feeding. In our study, the observed increase in fertility and hatchability for hens fed twice a day compared with those fed once, thrice and four times a day is consistent with results reported for some investigation (Spradley et al. 2008).

The physical characteristics of the egg, including egg weight, play an important role in the processes of embryo development and successful hatching (Narushin \& Romanov 2002). Spradley et al. (2008) believed that increased egg weight was related to providing feed later in the day (15.00) rather than feeding the hens twice a day. However, our results are consistent with the work of Taherkhani et al. (2010) that suggest that increased fertility and hatchability may be explained by a more efficient utilization of food due to an increased feeding frequency.

In the more-than-twice-a-day feeding treatments, maybe the stress caused by the increased feed allowance could be detrimental to fertility and hatchability. Kohne et al. (1973) reported that feeding time is a factor that may lead to heat stress, due to the heat increment from exothermic reactions that happen during feed metabolism. Splitting the daily feed allotment into a $75: 25$ ratio provides not only a sufficient volume of feed at both feeding times to minimize competition amongst the birds but also seems to reduce the heat stress in hens.

In conclusion, this study revealed that the best performance in terms of total egg production, fertility and hatchability is attained by feeding hens twice per day with $75 \%$ of the feed at 16.00 and $25 \%$ of the feed at 12.00 . 


\section{Acknowledgements}

This work was based on the MSc. thesis of first author and it was supported by the Islamic Azad University, Rasht Branch, Rasht, Iran, that we gratefully acknowledge. Also, the authors are grateful to Mohammad Golshani and Farhad Lotfi for the statistical analysis, data collection of birds, and supplying the experimental records used in this study.

The authors declare that they have no conflict of interest.

\section{References}

Backhouse D, Gous RM (2006) Responses of adult broiler breeders to feeding time. Worlds Poult Sci J 62, 269-281

Bootwalla SM, Wilson HR, Harms RH (1983) Performance of Broiler Breeders on Different Feeding Systems. Poult Sci 62, 2321-2325

Brake JD, McNaughton JL, Nachman RJ (1985) Delay of Onset of Oviposition in Pullets Promoted by 6-Methoxybenzoxazolinone. Poult Sci 64, 774-776

Cave NA (1981) Effect of Diurnal Programs of Nutrient Intake on Performance of Broiler-Breeder Hens. Poult Sci 60, 1287-1292

Clunies M, Etches RJ, Fair C, Leeson S (1993) Blood, intestinal and skeletal calcium dynamics during egg formation. Can J Anim Sci 73, 517-532

De Avila VS, Penz Jr AM, Rosa PS, de Brum PAR, Guidoni AL, Ledur MC (2003) Influence of feeding time on sexual maturity and carcass composition in female broiler breeders. Rev Bras Cienc Avic 5, 189-196

Gower JC (1971) A General Coefficient of Similarity and Some of Its Properties. Biometrics 27, 857-871

Kohne HJ, Boone MA, Jones JE (1973) The Effect of Feed Consumption on the Survival Time of Adult Turkey Hens Under Conditions of Acute Thermal Stress. Poult Sci 52, 1780-1783

Leeson S, Summers JD (2009) Broiler Breeder Production (Digital reprint). Nottingham University Press, Thrumpton, Nottingham, England, digitally reprinted from: University Books, Guelph, Ontario, Canada

Mano Y, Nirmal Kumar S, Basavaraja HK, Mal Reddy N, Datta RK (1993) A new method to select promising silkworm breeds/combinations. Indian Silk 31, 53

Moradi S, Zaghari M, Shivazad M, Osfoori R, Mardi M (2013) The effect of increasing feeding frequency on performance, plasma hormones and metabolites, and hepatic lipid metabolism of broiler breeder hens. Poult Sci 92, 1227-1237

Narushin VG, Romanov MN (2002) Egg physical characteristics and hatchability. Worlds Poult Sci J 58, 297-303

Renema RA, Sikur VR, Robinson FE, Korver DR, Zuidhof MJ (2008) Effects of Nutrient Density and Age at Photostimulation on Carcass Traits and Reproductive Efficiency in Fast- and Slow-Feathering Turkey Hens. Poult Sci 87, 1897-1908

Savory CJ (1977) Effects of egg production on the pattern of food intake of broiler hens kept in continuous light. Br Poult Sci 18, 331-337

Spradley JM, Freeman ME, Wilson JL, Davis AJ (2008) The Influence of a Twice-a-Day Feeding Regimen After Photostimulation on the Reproductive Performance of Broiler Breeder Hens. Poult Sci 87, 561-568

Taherkhani R, Zaghari M, Shivazad M, Zare Shahneh A (2010) A twice-a-day feeding regimen optimizes performance in broiler breeder hens. Poult Sci 89, 1692-1702

Tanabe Y, Ogawa T, Nakamura T (1981) The effect of short-term starvation on pituitary and plasma LH, plasma estradiol and progesterone, and on pituitary response to LH-RH in the laying hen (Gallus domesticus). Gen Comp Endocrinol 43, 392-398

Zakaria AH, Plumstead PW, Romero-Sanchez H, Leksrisompong N, Osborne J, Brake J (2005) Oviposition pattern, egg weight, fertility, and hatchability of young and old broiler breeders. Poult Sci 84, 1505-1509

King'ori AM (2011) Review of the Factors That Influence Egg Fertility and Hatchabilty in Poultry. Int J Poult Sci $10,483-492$ 